\title{
ĐỀ XUẤT QUY ĐỊNH ĐỘ CHÍNH XÁC VỊ TRÍ ĐIỂM TRÊN RANH GIỚI THỬA ĐẤT KHI TÍNH ĐẾN GIÁ TRỊ ĐẤT
}

\author{
ThS. NGUYẼ̃N PHI SONN \\ Viện Khoa học Đo đạc và Bản đồ
}

\section{Tóm tắt:}

Trong bài báo này sẽ trình bày kết quả tính toán và đưa ra đề xuất quy định về độ chính xác vị trí điểm trên ranh giới thửa đất theo cách tiếp cận từ góc độ giá trị kinh tế của đất, đất có giá trị kinh tế cao sẽ có yêu cầu cao về độ chính xác đo đạc. Xuất phát từ các mong muốn về giao dịch mua bán, chuyển nhượng, tính thuế, giao nhận diện tích... các thửa đất với sai số xác định giá trị thửa đất là nhỏ nhất, các nghiên cứu trước đây đã xác lập được quan hệ giữa yêu cầu sai số vị trí điểm trên ranh giới thửa đất và yêu cầu xác định giá trị của thửa đất. Từ quan hệ này kết hợp với kết quả điều tra trên 6 nhóm đất chính với 1000 thưa đất được điều tra, chúng ta tính toán được yêu cầu độ chính xác tương ứng với khu vực có giá trị kinh tế cao hơn cho từng loại đất chính.

1. Lập quan hệ giữa sai số vị trí điểm và giá trị đất

ai số xác định diện tích các thửa đất trong các giao dịch về đất đai rất quan trọng, nhất là đối với việc mua bán, chuyển nhượng, đền bù, quy hoạch, tính thuế .v.v..., đây là yếu tố trực tiếp để tính ra giá trị của một thửa đất bằng tiền tệ. Mọi chủ sử dụng đất đều hiểu rằng số liệu đo đạc để tính diện tích thửa đất đều có chứa một sai số nhất định so với diện tích "thực" của thửa đất, mà diện tích "thực" này không bao giờ có được giá trị đúng tuyệt đối. Vấn đề nằm ở chỗ sai lệch về diện tích phải là bao nhiêu mà chủ sử dụng đất chấp nhận được khi xác địinh giá trị tài sản đất đai phục vụ giao dịch bất động sản?. Để giải quyết vấn đề này đòi hỏi phải xác định được giá của các loại đất, sai số xác định gia của các loại đất và mức sai số diện tích thưa đất được các chủ sử dụng đất chấp nhận. Việc giải quyết vấn đề này cho phép xác định được độ chính xác đo đạc địa chính đối với các loại đất khác nhau.

Từ quan hệ $C=P \cdot C_{O}$, ở đây $C$ là giá trị của thửa đất, $P$ là diện tích thửa, $C_{o}$ giá của $1 \mathrm{~m}^{2}$ đất, chúng ta nhận được quan hệ:

$$
\left(\frac{m_{c}}{C}\right)^{2}=\left(\frac{m_{p}}{P}\right)^{2}+\left(\frac{m_{C_{0}}}{C_{0}}\right)^{2}
$$

Ơ đây $m_{C_{0}}$ là sai số trung phương khi ước tính giá đất;

$m_{P}$ là sai số trung phương xác định diện tích;

$\mathrm{m}_{\mathrm{c}}$ là sai số trung phương giá trị thửa đất.

Hà Minh Hòa (1999) đã chứng minh quan điểm các sai số trung phương (SSTP) tương đối của diện tích thửa đất được coi là 
nhỏ và được bỏ qua khi không vượt quá $1 / 3$ $\div 1 / 5$ (với mức trung bình của $1 / 4$ ) sai số trung phương xác định giá của $1 \mathrm{~m}^{2}$ đất, tức là từ (1) suy ra:

$$
m_{p} \leq \frac{1}{4} \frac{m_{C_{0}}}{C_{0}} P
$$

Từ công thức liên hệ giữa SSTP diện tích và SSTP vị trí điểm trong tài liệu [3]:

$$
m_{P}=\frac{m_{x y}}{2 \cdot \sqrt{2}}\left[\sum_{i=1}^{n} D_{i+1, i-1}^{2}\right]^{1 / 2},
$$

Ta tính được:

$$
m_{x y}=\frac{1}{4} \frac{m_{C_{o}}}{C_{o}} \sqrt{P} \sqrt{\frac{2 K}{1+K^{2}}}
$$

Ơ đây $\mathrm{K}$ là hệ số giữa chiều rộng trung bình trên chiều dài trung bình của thửa đất hình chữ nhật (thưa đất hình chữ nhật được chọn làm đại diện cho hình dạng của tất cả các thửa đất nghiên cưu).

Hà Minh Hòa (2008) đã tính toán được yêu cầu độ chính xác vị trí của góc thửa đất cho khu vực đô thị dựa trên giá trị các loại đất đô thị. Tuy nhiên, đối với đất nông nghiệp, phi nông nghiệp ở nông thôn chưa được tính toán cụ thể do chưa có số liệu điều tra thực tế.

Trong khuôn khổ đề tài "Nghiên cứu xác định độ chính xác đo vẽ bản đồ địa chính các loại đất để hoàn thiện, bổ sung một số quy định trong thành lập bản đồ địa chính ở nước ta”, đã tiến hành nghiên cứu quan hệ giữa độ chính xác vị trí điểm ranh giới thửa đất của các loại đất tương ứng theo giá trị kinh tế của đất, đảm bảo khu vực có giá đất cao sẽ được đo với độ chính xác cao hơn, trên cơ sơ kết qua điều tra thực tế 1000 thưa đất. Nội dung dưới đây sẽ trình bày kết quả thực nghiệm và đưa ra đề xuất các quy định về sai số vị trí điểm trên ranh giới thưa đất đối với các khu vực đất có giá trị kinh tế cao hơn.

\section{2. Điều tra thực tế xác định các thông tin thửa đất và sai số ước tính giá đất $m_{C_{0}}$ cho các loại đất}

Từ quan hệ giữa sai số trung phương xác định vị trí điểm ranh giới thửa đất và sai số trung phương xác định giá đất, diện tích thửa, hệ số kích thước thửa đất tại công thức (4), ta thấy SSTP vị trí điểm ranh giới thửa đất phụ thuộc vào sai số trung phương tương đối của ước tính giá đất cho $1 \mathrm{~m}^{2}$, đối với mỗi loại đất, mỗi khu vực, mỗi chủ sử dụng đất khác nhau sẽ có những ý kiến khác nhau về mức độ chấp nhận được sự chênh lệch này khi giao dịch mua bán quyền sử dụng đất. Khi đất có giá cao được ước tính giá đất với sai số tương đương với loại đất có giá thấp thì sự chênh lệch về giá tṛi là rất lớn. Ví dụ như $\frac{1}{300}$, tương ưng là $0,33 \%$, một thửa đất ở đô thị có giá 50 triệu đồng $/ \mathrm{m}^{2}$ tương ứng chênh lệch về giá trị do sai số trung phương tương đối của ước tính giá đất gây ra là 0,167 triệu đồng $/ \mathrm{m}^{2}$, trong khi đó đất nông nghiệp có giá 0,5 triệu đồng $/ \mathrm{m}^{2}$ nếu áp dụng cùng tương đương mức ước tính gia đất như trên là $0,33 \%$, thì chênh lệch do sai số trung phương tương đối ước tính giá đất gây ra là 0,00167 triệu đồng $/ \mathrm{m}^{2}$. Sự chênh lệch quá lớn giữa 2 loại đất này sẽ khó chấp nhận, trong thực tế sai số trung phương tương đối ước tính giá đất ở tại đô thị sẽ có xu hướng chặt chẽ hơn, mức 0,167 triệu đồng $/ \mathrm{m}^{2}$ sẽ không được người bán chấp nhận mà phải giảm xuống ở mức mà tâm lý người bán 
thấy "sự thiệt thòi" này là không đáng kể so với giá trị tài sản của họ, có thể chấp nhận được ở mức thấp hơn $0,33 \%$. Tuy nhiên, xét về mặt xã hội đây là vấn đề tâm lý của giao dịch mua bán trên thị trường, bất kỳ sự trao đổi nào đều có những mức chênh lệch về giá cả để "thuận mua - vừa bán". Chính vì vậy sai số này cần phải được khảo sát ở tất cả các loại đất, vùng miền, khu vực để có thể tính được một giá trị đại diện. Tiêu chí để khảo sát bao gồm các mẫu được điều tra trên các loại đất; ở các vùng khác nhau; ở các mức giá khác nhau; ở các vị trí khác nhau. Có như vậy sẽ đảm bảo cho sự đa dạng và khách quan trong kết luận chung về $\frac{m_{C_{0}}}{C_{0}}$ của mỗi loại đất. Giá trị được thiết kế trong các câu hỏi của 6 loại phiếu điều tra cho 6 nhóm đất.

Để giải nghĩa cho khái niệm và tránh nhầm lẫn, chúng ta xem ví dụ sau: Giả sử giá đất bình quân đang giao dịch tại khu vực của loại đất này là 100 ngàn đồng $/ 1 \mathrm{~m}^{2}$, khi mua bán thì giá thỏa thuận thành công là 96 ngàn đồng $/ 1 \mathrm{~m}^{2}\left(C_{0}\right)$ có nghĩa là mức chênh lệch trong mua bán có thể chấp nhận được là 4 ngàn đồng $/ 1 \mathrm{~m}^{2}\left(m_{C_{0}}\right)$, Chủ sư dụng đất coi mức chênh lệch 4 ngàn đồng $/ 1 \mathrm{~m}^{2}$ là chênh lệch đối với giá trị thực của $1 \mathrm{~m}^{2}$ đất mà thịi trương định giá, như vậy $\frac{m_{C_{0}}}{C_{0}}=\frac{4}{96}=$ 0,04167 . Chỉ tiêu điều tra là $C_{0}$ vă $m_{C_{0}}$.

Việc điều tra thực tế về mức chênh lệch giữa giá đất chuẩn của khu vực và giá đất chuyển nhượng thành công chính là việc xác định sai số trung phương tương đối của giá đất. Thực chất của cuộc điều tra này là lấy được ý kiến chủ quan của các chủ sử dụng đất về mong muốn các sai số trong quá trình xác định giá trị mảnh đất phải nhỏ nhất, mà 2 sai số tác động đến việc xác định giá trị này là "sai số ước tính giá đất" và "sai số đo đạc diện tích của thửa đất", công thức (4) đã xác lập quan hệ này. Sai số trung phương tương đối của giá đất của mỗi loại đất sẽ khác nhau, một phần do giá trị đất mang lại, đất có giá trị cao đòi hỏi phải được tính giá đất chặt chẽ hơn, đất có giá trị không cao sẽ không đòi hỏi khắt khe như khu vực đất đai có giá trị cao. Như vậy có thể thấy rằng đất càng có giá trị cao thì sai số trung phương tương đối của ước tính giá đất càng phải nhỏ và ngược lại.

Ngoài việc điều tra giá đất, các thông tin về thửa đất cũng được thu thập đầy đủ. Đối với giá đất $C_{0}$ sẽ được điều tra là giá thị trường thông qua chuyển nhượng, đền bù, đấu giá ở địa phương. Do các thông tin chuyển nhượng ở thị trường ở một số vị trí còn hạn chế, vì vậy khi điều tra đã phải kiểm chứng mức giá chung của khu vực để tránh các sai số thô khi điều tra.

Từ kết quả điều tra các chỉ tiêu: $K, P, \frac{m_{c_{0}}}{C_{0}}$

của mỗi thửa đất, chúng ta tính được giá trị $m_{x y}$ của mỗi thửa đất thông qua công thức (4), như vậy trong mỗi nhóm đất chúng ta sẽ tính giá trị trung bình $m_{x y}$ cho nhóm đất đó và đó chính là sai số trung phương vị trí điểm trên ranh giới thửa đất có giá trị kinh tế cao của nhóm đất đó.

\section{Kết quả tính toán yêu cầu độ chính} xác vị trí điểm ranh giới thửa đất theo số liệu điều tra thực tế

Từ kết quả điều tra của các nhóm đất: nhóm đất phi nông nghiệp tại đô thị với 220 thửa, nhóm đất phi nông nghiệp tại nông thôn với 210 thửa, nhóm đất nông nghiệp với 200 thửa; nhóm đất lâm nghiệp với 120 thửa; nhóm đất nuôi trồng thủy sản và làm muối với 60 thửa, kết quả tính toán yêu cầu 
độ chính xác vị trí điểm trên ranh giới thửa đất đối với đất có giá trị cao hơn được trình bày ở bảng dưới đây, (trong bảng có so sánh với quy định trong Quy phạm 2008).

Độ chính xác vị trí điểm trên ranh giới thửa đất được đề xuất tại bảng này, được đề nghị áp dụng đối với các khu vực mà giá trị kinh tế đất cao hơn, yêu cầu của công tác quản lý, quy hoạch các khu đô thị, các thửa đất mặt đường, mặt phố, trung tâm đô thị....Như vậy, trong cùng một loại đất đo vẽ, khu vực có giá trị kinh tế cao hơn sẽ có yêu cầu về sai số trung phương vị trí điểm trên ranh giới thửa đất biểu thị trên bản đồ địa chính số so với vị trí của điểm khống chế đo vẽ gần nhất phải cao hơn các khu vực cùng loại đất còn lại.

\section{Kết luận}

Việc nghiên cứu để điều chỉnh các quy định hiện nay về đo đạc thành lập bản đồ địa chính nói chung và điều chỉnh quy định về độ chính xác đo vẽ bản đồ nói riêng theo hướng chặt chẽ hơn là việc làm cần thiết, phù hợp với sự phát triển đi lên của xã hội khi công nghệ thiết bị tiên tiến đã từng bước áp dụng trong đo đạc làm tăng độ chính xác của sản phẩm địa chính. Đặc biệt, khi đất

\begin{tabular}{|c|c|c|c|c|}
\hline \multirow{2}{*}{ Loại đất } & \multirow{2}{*}{$\begin{array}{c}\text { Tỷ lệ bản } \\
\text { đồ }\end{array}$} & \multicolumn{2}{|c|}{$\begin{array}{l}\text { Độ chính xác vị trí điểm ranh } \\
\text { thửa của Quy phạm } 2008\end{array}$} & \multirow{2}{*}{\begin{tabular}{|c|}
$\begin{array}{c}\text { Độ chính xác đối với các khu vực } \\
\text { đất có giá trị kinh tế cao hơn }\end{array}$ \\
Sai số trung phương \\
\end{tabular}} \\
\hline & & $\begin{array}{l}\text { Sai số trung } \\
\text { bình }\end{array}$ & $\begin{array}{l}\text { Sai số trung } \\
\text { phương }\end{array}$ & \\
\hline \multirow{3}{*}{$\begin{array}{l}\text { Đối với khu } \\
\text { vực đô thị }\end{array}$} & $1 / 200$ & $5 \mathrm{~cm}$ & $6,25 \mathrm{~cm}$ & $4,5 \mathrm{~cm}$ \\
\hline & $1 / 500$ & $7 \mathrm{~cm}$ & $8,75 \mathrm{~cm}$ & $6,3 \mathrm{~cm}$ \\
\hline & $1 / 1000$ & $15 \mathrm{~cm}$ & $18,75 \mathrm{~cm}$ & $11,6 \mathrm{~cm}$ \\
\hline \multirow{2}{*}{\begin{tabular}{|c|} 
Đối với đất ở \\
và đất chuyên \\
dùng khu vực \\
nông thôn
\end{tabular}} & $1 / 1000$ & $15 \mathrm{~cm}$ & $18,75 \mathrm{~cm}$ & $12,5 \mathrm{~cm}$ \\
\hline & $1 / 2000$ & $30 \mathrm{~cm}$ & $37,51 \mathrm{~cm}$ & $21,6 \mathrm{~cm}$ \\
\hline \multirow{3}{*}{\begin{tabular}{|} 
Đối với khu \\
vực đất sản \\
xuất nông \\
nghiệp trồng \\
cây hàng năm
\end{tabular}} & $1 / 1000$ & $15 \mathrm{~cm}$ & $18,75 \mathrm{~cm}$ & $13,1 \mathrm{~cm}$ \\
\hline & $1 / 2000$ & $30 \mathrm{~cm}$ & $37,50 \mathrm{~cm}$ & $27,4 \mathrm{~cm}$ \\
\hline & $1 / 5000$ & $150 \mathrm{~cm}$ & $187,5 \mathrm{~cm}$ & $90,9 \mathrm{~cm}$ \\
\hline \multirow{2}{*}{$\begin{array}{l}\text { Đối với khu } \\
\text { vực đất sản } \\
\text { xuất nông } \\
\text { nghiệp trồng } \\
\text { cây lâu năm }\end{array}$} & $1 / 2000$ & $30 \mathrm{~cm}$ & $37,50 \mathrm{~cm}$ & $33,6 \mathrm{~cm}$ \\
\hline & $1 / 5000$ & $150 \mathrm{~cm}$ & $187,5 \mathrm{~cm}$ & $137,2 \mathrm{~cm}$ \\
\hline \multirow{2}{*}{\begin{tabular}{|} 
Đối với khu \\
vực đất nuôi \\
trồng thủy \\
sản, làm muối
\end{tabular}} & $1 / 2000$ & $30 \mathrm{~cm}$ & $37,50 \mathrm{~cm}$ & $33,2 \mathrm{~cm}$ \\
\hline & $1 / 5000$ & $150 \mathrm{~cm}$ & $187,5 \mathrm{~cm}$ & $151,2 \mathrm{~cm}$ \\
\hline \multirow{2}{*}{\begin{tabular}{|c|} 
Đối với khu \\
vực đất lâm \\
nghiệp và đất \\
chưa sử dụng
\end{tabular}} & $1 / 5000$ & $150 \mathrm{~cm}$ & $187,5 \mathrm{~cm}$ & $158,1 \mathrm{~cm}$ \\
\hline & $1 / 10.000$ & $300 \mathrm{~cm}$ & $375,0 \mathrm{~cm}$ & $230,2 \mathrm{~cm}$ \\
\hline
\end{tabular}


đai là nguồn tài nguyên ngày càng quý giá, độ chính xác của bản đồ là yêu cầu trở lên quan trọng nhất trong các giao dịch về đất đai, trên thị trường bất động sản, trong hồ sơ địa chính cần quản lý... Nhà nước là chủ sở hữu và các tổ chức và người dân là chủ sử dụng của đất đai đều mong muốn diện tích của mỗi thửa đất đều được đo đạc với độ chính xác cao nhất, trên tất cả các loại đất ở tất cả các vùng miền và nhất là đối với các loại đất ở, đất sản xuất kinh doanh, đất nông nghiệp đang tạo ra hiệu quả kinh tế cao... Chính vì vậy, việc nghiên cứu để xem xét trong từng điều kiện, từng loại đất cụ thể, ở các khu vực có giá trị kinh tế cao phải được đo vẽ thành lập bản đồ với yêu cầu độ chính xác vị trí điểm, độ chính xác tương hỗ cạnh, độ chính xác diện tích thửa đất cao hơn đáp ứng yêu cầu của xã hội, từng bước nâng cao chất lượng của bản đồ địa chính, phục vụ hiệu quả cho công tác quản lý đất đai. Xuất phát từ đó, chúng ta cần phải xem xét đến việc đưa kết quả nghiên cứu như trong bài báo này vào thực tiễn. Đặt ra yêu cầu độ chính xác cao hơn khi đo vẽ thành lập bản đồ những khu vực đất có giá trị kinh tế cao là yêu cầu hết sức quan trọng, ngoài việc nâng cao chất lượng của bản đồ địa chính ở những khu vực đất đai có giá trị sử dụng cao mà còn tạo tiền đề cho hướng xây dựng tiêu chuẩn kỹ thuật đo đạc địa chính (Cadastral Survey) cho thành lập "bản đồ địa chính tùy biến" (không phụ thuộc vào tỷ lệ bản đồ mà phụ thuộc vào loại đất và giá trị đất).

Việc đề xuất khu vực đất có giá trị cao để đưa ra yêu cầu đo vẽ với độ chính xác cao hơn là xuất phát từ yêu cầu của công tác quản lý đất đai của các cấp địa phương. Sự phân biệt tương đối giữa khu vực đất có giá trị kinh tế cao hơn đối với các khu vực còn lại trong cùng một nhóm đất là công việc phải được tiến hành trong quá trình khảo sát, lập thiết kế kỹ thuật dự toán để xác định được khối lượng cần đo vẽ trong cùng một tỷ lệ nhưng với độ chính xác vị trí điểm cao hơn, kể cả trường hợp trên cùng một mảnh bản đồ có thể quy định 2 hoặc 3 độ chính xác. Vấn đề của một nghiên cứu tiếp theo là luận chứng cho việc xác định phạm vi của các khu vực được gọi là khu vực đất có giá trị cao. O

\section{Tài liệu tham khảo}

[1]. Bộ Tài nguyên và Môi trường (2008) Quy phạm thành lập bản đồ địa chính tỷ lệ $1 / 200,1 / 500,1 / 1000,1 / 2000,1 / 5000$, $1 / 10.000$ được ban hành kèm theo Quyết định số 08/2008/QĐ-BTNMT ngày 10/11/2008.

[2]. Hà Minh Hòa (1999) Bàn về thiết kế đo đạc trắc địa trong việc thành lập bản đồ địa chính. Tạp chí địa chính, số 7 , tháng 7/1999 - Trang 6 - 9.

[3]. Hà Minh Hòa (2008) Bàn về việc xây dựng một số tiêu chuẩn kỹ thuật đo đạc địa chính bằng máy toàn đạc điện tử. Tạp chí địa chính, số 4, tháng 8/2008 - Trang 4 - 10.

[4]. Nguyễn Phi Sơn (2012) "Nghiên cứu xác định độ chính xác đo vẽ bản đồ địa chính các loại đất để hoàn thiện, bổ sung một số quy định trong thành lập bản đồ địa chính ở nước ta". Đề tài $\mathrm{KHCN}$ cấp Bộ, tháng 12/2012.

[5]. Hướng dẫn khảo sát địa hình tỷ lệ $1: 5000,1: 2000,1: 1000$ và $1: 500$, Maxcova GUGK phê duyệt ngày 31 tháng ba 1972 (M. Nedra năm 1973). $O$

(Xem tiếp trang 48) 